Edith Cowan University

Research Online

Research outputs 2014 to 2021

2020

\title{
The influence of adaptive challenge on engagement of multidisciplinary staff in standardising aseptic technique in an emergency department: A qualitative study
}

\author{
Amanda Towell-Barnard \\ Edith Cowan University \\ Susan Slatyer \\ Helen Cadwallader \\ Michelle Harvey \\ Susan Davis \\ Edith Cowan University
}

Follow this and additional works at: https://ro.ecu.edu.au/ecuworkspost2013

Part of the Nursing Commons

10.1111/jocn.15109

This is the peer reviewed version of the following article:

Towell-Barnard, A., Slatyer, S., Cadwallader, H., Harvey, M., \& Davis, S. (2020). The influence of adaptive challenge on engagement of multidisciplinary staff in standardising aseptic technique in an emergency department: $\mathrm{A}$ qualitative study. Journal of Clinical Nursing, 29(3-4), 459-467. https://doi.org/10.1111/jocn.15109, which has been published in final form at https://doi.org/10.1111/jocn.15109. This article may be used for noncommercial purposes in accordance with Wiley Terms and Conditions for Use of Self-Archived Versions. This Journal Article is posted at Research Online. https://ro.ecu.edu.au/ecuworkspost2013/7183 
Running head: Adaptive challenge and aseptic technique

The influence of adaptive challenge on engagement of multidisciplinary staff in standardising aseptic technique in an emergency department: A qualitative study.

\section{Abstract}

\section{Aims and objectives}

To explore the challenge of engaging multidisciplinary staff in standardising aseptic technique (AT) in an emergency department (ED) in an Australian tertiary hospital, and to better understand the enablers and barriers to implementing practice change within this setting.

\section{Background}

Healthcare associated infections are the most common complication for patients in acute care. A clinical practice framework developed in the United Kingdom (UK) standardised AT practice to reduce potential infection risk. One Australian tertiary hospital drew upon this framework to similarly improve clinical practice. It was understood that standardising practice would require some practitioners only to revisit and demonstrate AT principles already embedded in their practice, whilst others would be challenged to adopt a new approach.

\section{Design}

Qualitative, descriptive research design.

\section{Methods}

Data were collected through focus groups held before and after implementation of the AT program. Data were analysed using the Framework Method. The (COREQ) checklist was followed.

\section{Results}

Four emergent themes described the influence of motivation on individuals' beliefs and attitudes towards practice change, relationships within the ED context, delivery of education, and management directives.

\section{Conclusion}


Running head: Adaptive challenge and aseptic technique

Implementing practice change is more than just providing technical knowledge and includes changing individuals' beliefs and attitudes. An understanding of adaptive challenge can assist in implementing practice change that involves the multidisciplinary team.

\section{Relevance to clinical practice}

Results provide evidence as to how the adaptive challenge framework could be a suitable approach to manage potential enablers and barriers to implementing change within a multidisciplinary team in an acute hospital.

\section{Keywords}

Adaptive challenge

Engagement of multidisciplinary team

Aseptic technique

Qualitative

Emergency department.

\section{What does this paper contribute to the wider global clinical community?}

- Practice change is more than providing technical information and may include motivation to challenge individuals' beliefs and attitudes;

- The adaptive challenge framework can assist in implementing practice change involving the multidisciplinary team within an ED setting;

- Strategies to engage ED practitioners in practice change include consistent communication, provision of evidence underpinning the need for and impact of the standardised practice, early structured education, and use of opinion leaders such as local champions. 
Running head: Adaptive challenge and aseptic technique

\section{Introduction}

Invasive procedures put hospitalised patients at significant risk of health care associated infections and, consequently, increase morbidity and mortality (Rowley \& Clare, 2011). In Australia, health care associated infections are the most common complication for patients in acute care, with around 165,000 occurring each year (Mitchell, Shaban, MacBeth, Wood, \& Russo, 2017). Health professionals use techniques to minimise the introduction of microorganisms when introducing or handling invasive equipment (Aziz, 2009). However, evidence from the United Kingdom (UK) suggests that clinicians' aseptic technique (AT) practice and consequent risk to patients varies (Aziz, 2009; Rowley \& Clare, 2009). A strategy to minimise this risk is to standardise AT practice amongst clinical staff undertaking invasive procedures. In the UK, the Aseptic Non Touch Technique (ANTT) ${ }^{\circledR}$ clinical practice framework has been widely implemented to address this source of potential clinical risk (Rowley, Clare, Macqueen, \& Molyneux, 2010).

The central premise of $\mathrm{ANTT}^{\circledR}$ is the principle of 'asepsis' and the standardisation of the technique for all invasive procedures, regardless of complexity (Rowley \& Clare, 2011). Evidence demonstrates improvement with the reduction of infection rates in hospitals where AT was standardised (Rowley et al., 2010). One Australian hospital drew on the principles of ANTT $^{\circledR}$ to standardise AT practice. An education program was developed for the nursing, medical, and allied health staff. This program included knowledge on risks associated with poor AT, application of principles of AT, and competency assessments. This practice change within the organisation required that some practitioners adopt a new approach to AT, while others needed only to revisit previously learnt AT principles and demonstrate competence in practice.

Many practice change projects fail because of the adaptive challenge (Pronovost, 2011). Instances where individuals' deeply held beliefs are challenged, and values that have 
Running head: Adaptive challenge and aseptic technique

previously been successful becomes less relevant require adaptive work (Heifetz \& Laurie, 1997). Accordingly, actions are needed to address the values, beliefs and attitudes of the group involved with the change (Pronovost, 2011).

\section{Background}

The complexity of introducing change increases when practitioners' long-held beliefs are challenged (Edwards, Sevdalis, Vincent, \& Holmes, 2012; Rowley \& Clare, 2009). Studies reporting variable adoption of clinical practice guidelines by ward and hospital staff members (Rowley \& Clare, 2009), or by individual practitioners (Grol, 2001), have illuminated the influence of the practice environment and practitioners' attitudes. Practice change requires leadership, engagement, communication, and teamwork to be effective (Rangachari, Rissing, \& Rethemeyer, 2013). While education is essential, sustainable change requires an understanding of the practice context, barriers that must be addressed, and factors likely to enable clinician engagement in the initiative (Rangachari et al., 2013). A review of communication in relation to infection control in acute health care has emphasised the influence of social and cultural factors on individuals' behaviour (Edwards et al., 2012).

The theory of adaptive challenge provides a conceptual framework to facilitate practice change. Adaptive challenges can be differentiated from technical problems because they can only be addressed when people change their values and beliefs (Pronovost, 2011). Technical problems are easy to identify, occur in one or two places, and lend themselves to clear-cut resolutions. People are generally receptive to technical solutions, which are quickly implemented, often by an expert. In contrast, a problem that is difficult to define and has a seemingly elusive solution is usually an adaptive challenge (Haeusler, 2010). Resolution requires changes in peoples' attitudes and ideas. Rather than providing a single solution, adaptive challenges require people to work with the problem and toward solving it (Heifetz, 
Running head: Adaptive challenge and aseptic technique

Linsky, \& Grashow, 2009). A common reason underlying the failure of practice change is the use of technical solutions to address adaptive challenges (Pronovost, 2011). Therefore, the major theme of the adaptive challenge approach is that in order for change to take place and be maintained, people need to be able to amend their beliefs, values and attitudes (Pronovost, 2011).

The aim of this study was to explore the adaptive challenges when engaging multidisciplinary staff in practice change to standardise AT in the emergency department (ED) of an Australian tertiary hospital. The standardised AT program was implemented throughout the hospital and evaluated in ED, a discrete unit in which the multidisciplinary team frequently conducted invasive procedures.

\section{Objectives}

The specific objectives were to:

- Explore and describe the nursing and medical staff perspectives of implementing standardised AT in the ED;

- Explore and describe nursing and medical staff members' perceptions of standardised AT; and their perceived benefits and losses associated with its implementation;

- Identify barriers and enabling factors in the local practice environment to implementation of standardised AT; and

- Explore and describe ED nursing and medical staff perceptions of adaptive strategies to facilitate multidisciplinary engagement in implementing standardised AT. 
Running head: Adaptive challenge and aseptic technique

\section{Methods}

\section{Design}

This study used a qualitative, descriptive approach to explore adaptive challenge as an influence in standardising AT practice in this ED. This approach is suitable for health research as it aims to provide a comprehensive summary of the events being researched, when straight description of the data is required (Schneider, Whitehead, LoBiondo-Wood, \& Haber, 2014).

\section{Participants}

The setting for this study was the ED of a 608-bed tertiary hospital in Perth, Western Australia. On average, the ED receives over 60,000 presentations annually, of which $55 \%$ are admitted. There were 93 medical and 180 nursing staff employed in the department. Purposive sampling was used to recruit medical and nursing staff in ED for focus groups held before implementation of standardised AT, and to recruit nursing staff for postimplementation focus groups. The only exclusion criterion was staff who did not provide written informed consent. The sample consisted of registered nurses $(n=38)$ and doctors $(n=9)$. Data saturation was achieved when the data became repetitive and no new themes emerged (Schneider et al., 2014).

\section{Implementation of standardised AT}

Acute care settings are dynamic practice environments where staff routinely perform a variety of procedures requiring AT. While healthcare workers learn the principles of asepsis and how to operationalise these during undergraduate studies, over time their experiences, habits, and beliefs lead to variations in practice. In this hospital, the implementation of an education program to standardise AT provided staff with opportunities to reflect upon their practice, re-envision sources of risk to patients, and update skills to address these risks. 
Running head: Adaptive challenge and aseptic technique

A multidisciplinary working party was convened to drive implementation of the AT program across the hospital. A risk matrix, adapted from an assessment tool developed by the Australian Commission on Safety and Quality in Healthcare (Australian Commission on Safety and Quality in Health Care, 2012) identified two invasive procedures deemed to pose increased risk to patients based on clinical context, treatment type, and how recently the health practitioner's procedural technique had been assessed. These were: a) peripheral intravenous cannulation; and b) insertion of indwelling urinary catheters, both of which were performed frequently in the ED.

A marketing program introduced staff to the impending standardisation of AT practice. It was anticipated that for most staff members no significant change would be required, but rather that a proposed education program would reinforce existing knowledge and skills. However, anecdotal evidence emerged indicating that there was considerable variation in staff AT practice, suggesting that some may encounter challenges to how they perceive and address infection risk. Prior to the implementation, all disciplines were invited to attend an interactive AT workshop. Clinical leaders demonstrated AT relating to specific procedures including wound care, insertion of peripheral intravenous catheters, suctioning, and insertion of indwelling urinary catheters. This forum was an opportunity to showcase the logical and planned approach to standardising AT, while inviting questions in a non-threatening environment and enabling staff to envisage the impact for their practice.

A working party was formed with visible executive support and multidisciplinary representation. Members from the Nursing Executive Committee, medical, nursing, allied health, nursing education, and the Infection Prevention and Control department developed an education program.

\section{Education program}


Running head: Adaptive challenge and aseptic technique

This program included a hospital-wide campaign to increase awareness of the impending requirement for all staff performing invasive procedures to attend training and demonstrate competence in AT, plus the rationale for the change. The information was shared with the staff using a variety of media including hospital email, newsletters, flyers, staff forums, and AT storyboards in clinical areas.

The education program provided theory and practical assessment using the Train the Trainer model (Gleeson, 2017). The program incorporated an e-learning package developed by the Infection Prevention and Control Unit in conjunction with nurse educators, which focused on AT practice and principles underpinning the $\mathrm{ANTT}^{\circledR}$ framework (Rowley et al., 2010). Initial workshops included nurse educators, clinical leaders in wound care and intravenous therapy, and an allied health professional (podiatry).

Standardised education was supplemented with introduction of a formal process requiring staff to demonstrate competence in AT to a trained assessor. Demonstrated skills were assessed against a standardised tool. Direct feedback provided further opportunity for the staff member to reflect on their practice, and for the assessor to explore and, constructively, challenge beliefs underlying evident deficiencies in practice.

\section{$\underline{\text { Staff Development Nurses as change leaders }}$}

Staff development nurses at a local level played an important role in engaging staff in the implementation of the AT education program. These senior members of staff had a recognised education role, expertise and relationship with ward staff. This enabled them to provide leadership and guide their colleagues' perceptions and beliefs about AT practices.

ANTT $^{\circledR}$ resources were adapted to meet the specific needs of the organisation. A suite of clinical guidelines, policies, e-learning products, face-to-face presentations, and education 
Running head: Adaptive challenge and aseptic technique

updates were used to communicate a consistent unified approach to AT across the organisation.

Ethical approval was obtained from the Human Research Ethics Committees of both the study hospital and administering university. Participants were assured that participation was voluntary, and that confidentiality would be protected. All participants signed a consent form before data collection commenced.

\section{Data collection}

Data were collected using focus groups with ED nursing and medical staff to explore factors influencing their engagement with the requirement to standardised AT. Three focus groups were conducted prior to implementation of the AT program to explore attitudes to change in this setting, and any anticipated barriers and enabling factors. A further two focus groups were conducted following implementation to explore staff members' experiences of the AT education and application in practice, attitudes toward the change, and actual barriers and enablers encountered.

Two researchers conducted all focus groups and were not known to any of the participants. One researcher guided the focus group with a series of pre-determined open-ended questions and additional prompts to explore emerging ideas and concepts. The second researcher wrote memos during the focus groups to capture thoughts prompted by the discussion, and any observed behaviours and events.

The focus groups took place in a private room within ED but away from clinical areas, were audio recorded, and lasted between 45 to 60 minutes (nursing staff) and 20 minutes (medical staff). The introductory question explored participants' perceptions of AT and its meaning for their practice. Further questions sought participants' attitudes to changes required to standardise AT and their implications for practice. Lastly, questions guided 
Running head: Adaptive challenge and aseptic technique

participants to specifically reflect on anticipated and actual barriers and facilitators to effective implementation of the program.

\section{Data analysis}

The audio-recordings were transcribed verbatim. Random samples of transcripts were checked by the primary investigator for accuracy against the audio-tapes. Data were analysed using the Framework Method approach which is a form of qualitative analysis and is used to structure data in matrix form (Gale, Heath, Cameron, Rashid, \& Redwood, 2013). The matrix is used to systematically summarise and reduce the data to identify commonalities and differences (Gale et al., 2013).

Open-coding was conducted by three experienced qualitative researchers who independently examined each transcript line-by-line, identifying salient words, phrases and sentences. The aim was to classify all data in order for it to be systematically compared with other parts of the data set (Gale et al., 2013). The next stage involved grouping the codes into categories or themes. In grouping themes, a working analytical framework was developed (Gale et al., 2013). The framework focussed on barriers and facilitators to the adaptive challenge of standardising AT practice. Analysis progressed and sub-themes emerging from the data were coded inductively and added to the framework.

Trustworthiness refers to research findings being sufficiently faithful to the perspectives of participants for their implications to be acted upon (Guba \& Lincoln, 2005). Strategies used to ensure trustworthiness of the findings included; triangulation through collection of data from nursing and medical staff perspectives; involvement of multiple researchers to independently code the transcripts and resolve inconsistencies; and inclusion of exemplar quotations to demonstrate fit with the reported themes. Reporting of the study findings adheres to the COREQ checklist, see Supplementary File 1. 
Running head: Adaptive challenge and aseptic technique

\section{Results}

\section{Themes of barriers and facilitators}

Three pre-implementation focus groups included 21 nursing and nine medical staff participants. The two post-implementation focus groups were conducted with nursing staff $(n=17)$ four months following introduction of the AT program. By this time, $60 \%$ of the ED nursing staff had received AT education, which was considered sufficient for penetration of the principles into practice. Focus groups were not held with the medical staff as they were yet to receive the AT implementation program. Four key themes were identified in the data, which were: Motivation, Relationships, Education content and delivery, and Management directive. Table 1 presents a brief definition of each theme, with examples of adaptive challenges (barriers) and examples of possible adaptive leadership (facilitators).

\section{Motivation}

These data indicated that provision of evidence, specifically of improved patient outcomes, was instrumental to engaging staff members in the need for proposed change to practice and sustaining the change. Compelling evidence could change and strengthen beliefs about the perceived need for change. The belief that a new practice would bring benefit saw nurses invest in and champion the change:

If there's a decent reason behind it, people will comply but if people aren't understanding why [they won't] . . . . if I can't understand the reason behind it, l'd be less likely to enforce it on other people in my team as well.

(Nurse, FG1)

Medical staff also called for evidence challenging current practice, and by extension their belief in current approaches, before engaging in the change, such as, 'If someone can show us that it actually makes a difference, that's one thing ... [where's] the evidence?' (Doctor, FG3)

Sustaining motivation to continue the new practice then required integration of evidence from the local setting to consolidate staff members' belief that the desired practice was beneficial. 
Running head: Adaptive challenge and aseptic technique

Most meaningful were improving patient outcomes such as, 'infection rates . . information on how we are doing' (Nurse, FG1). This ongoing feedback tended to reassure those who were feeling challenged by process of change, because, 'you would get people more willing to participate because they're going, 'ok there is improvement here" (Nurse, FG1).

Nursing and medical participants' beliefs in themselves as accountable health professionals were also seen to influence their motivation to engage with the need for practice change and to suggest possible solutions when given evidence. Reflecting on the immediacy of clinical problems encountered in the ED, one doctor described a perceived need to weigh risk and benefit of a specific situation before deciding whether the proposed practice was appropriate. His belief in the need to exercise autonomy to protect the patient from the perceived greater clinical risk was evident when he remarked, 'there's a departmental policy and then it's your individual choice whether you choose to follow it or not [depending on clinical priorities]' (Doctor, FG3). These data indicated that staff members saw themselves as autonomous decision makers, accountable for their practice choices. However, they were also cognizant of their role in the ED team and the influence team relationships had on their and others' engagement with the practice change.

\section{Relationships}

Relationships include supporting members of the team to foster change and to do 'the right thing' through peer support and peer pressure.

It was evident that social relationships within the ED influenced how staff members supported each other to integrate new approaches into routine practice. Generally, nurses saw scope to interact with multi-disciplinary colleagues in order to promote implementation of AT within the unit. The majority also felt confident trying to influence the practice of medical staff. In part this was thought to be due to the ED culture in which: 
Running head: Adaptive challenge and aseptic technique

... people are stronger in telling; say doctors ... 'you can't do that. You must use a [cannulation] pack' ... I think part of it is the different culture that we have down here, like the relationship between medical and nursing ... there's more of an oversight in ED I think than up on the wards ... I'm more comfortable saying that now down in ED because we work a lot closer.

(Nurse, FG 4)

It was also evident that as the team worked together, collegial relationships developed that enabled nurses to advocate for improved practice, in this case the uptake of standardised AT. The idea of promoting practice change by 'nurse champions' was seen as a useful organisational strategy to facilitate a shared understanding of AT principles underpinning standardised practice across disciplines.

\section{Education content and delivery}

The third theme to emerge related to nurses' perceptions of the structure needed to introduce, implement and evaluate the change in AT practice. Suggestions included providing supporting evidence; tailoring to the healthcare setting and specific unit environment; relevance to multidisciplinary team members; and feedback mechanisms to generate and disseminate evidence to sustain motivation.

The provision of education within ED emerged from the data as a fundamental to facilitate uptake of AT practice change, and it was important that, 'the education needs to be properly done in the beginning' (Nurse, FG1). The implication was that education was a conduit for evidence with which to build the case for change. Additionally, education sessions provided opportunity to acknowledge, explore and, potentially, challenge individuals' beliefs about their own practice and introduce AT in a positive light. Nurses appreciated receiving this structured education that conveyed, through the investment in time and resources, the value of standardised AT practice. In contrast: 
Running head: Adaptive challenge and aseptic technique

Doctors don't get the same level of orientation to ED ... we [nurses] get cannulation competency. They explain that you have to wear sterile gloves, AT . . doctors just come in on their first day and they're slammed with 40 patients.

(Nurse, FG2)

In turn, one doctor described learning 'by osmosis' (Doctor, FG 3), which meant:

You have the [undergraduate] training ... but you learn on the job. People learn to put cannulas and learn AT from ... observing other people doing it. And so if the person teaching them isn't doing it the right way, they'll learn it not the right way as well.

(Doctor, FG 3)

Inter-professional education was believed to be the ideal approach to building a shared understanding of AT principles and standardised practices. Preferable timing was at the point of orientation, which meant:

You were told when you start here, and all the new doctors as well and the new nursing staff, "this is how we do it here". Yeah, its multidisciplinary ... all the specialties are educated, not just the nurses.

(Nurses, FG1)

A further organisational strategy to supplement the education program was seen to be the issuing of a practice directive.

\section{Management directive}

While education was considered important to engage staff in the need for practice change, it was most effective when supported with strong direction from management. Education could provide evidence of the problem and allow input for possible solutions, but mandating change helped overcome resistance boosting uptake of new practices.

I think you just educate, you bring it in. That's it, people just comply . . . 'this is practice. This is going to happen, deal with it guys' . . you end up being in the minority if you don't do it. You will get pulled aside. 
(Nurse, FG1)

Additionally, a consistent message from local team leaders who were well placed to champion standardised AT practice, was thought important to keep the need for change 'front of mind'. For one nurse, this meant:

The manager ... three or four of them having the same message ... [I think] 'it is real. Ok, I will do it' ... all of them, the CNM, CNS, everyone's having the same message every morning.

(Nurses, FG1)

\section{Discussion}

The central theme of adaptive challenge is that people will change their behaviour when they modify their values, beliefs, and attitudes (Pronovost, 2011). This study explored influences on nursing and medical staff members' engagement with practice change required to standardise AT within a busy hospital ED though the lens of adaptive challenge. In this setting, staff saw themselves as autonomous decision makers, who made clinical choices based on perceived relative risk and benefit to their patients. The findings indicated that providing evidence of the need to change practice and allowing staff time to engage with possible solutions tended to promote implementation. Then throughout the implementation, feedback in the form of evidence showing the effects of change was considered important to embed the change in practice. Structured education and management directives were thought useful organisational strategies to raise awareness of the need for change and to guide preferred practice. However, the extent to which individuals engaged with the directed change was seen to contingent upon their view of competing clinical priorities, shaped by beliefs about sources of risk, potential benefits to patients, and appropriateness of the proposed practice. 
Running head: Adaptive challenge and aseptic technique

The four emergent themes reflect key principles known to facilitate adaptive change: 1) have a consistent goal and invite everyone to help achieve it; 2) acknowledge real and perceived losses; 3) communicate the need for change; 4) identify staff members' interests to maximise perceived benefits and minimise losses; 5) seek to understand rather than judge; and 6) monitor the organisational pressure (Heifetz et al., 2009). The relevance of these six principles is that they can inform adaptive strategies to address practice change program.

Rather than providing a single solution, adaptive challenges require people to work with the problem and toward solving it (Heifetz et al., 2009). In the current study, one of the strongest themes to emerge from the data was the need to provide evidence of a problem and the proposed solution as a motivator for the staff to consider changing their practice. Motivation can be either 'internal' and/or 'external' as drivers for implementing the proposed change (Schinnerer, 2018). Internal motivation exists within the individual health practitioner, as seen in these ED staff who saw themselves as autonomous and accountable for their own practice. External motivation can be in the form of peer support and the provision of evidence to support the need for change.

This finding aligns with the adaptive leadership principle of communicating the need for change, seeking to understand a problem's cause rather than judging, and giving those impacted by a potential change a clear rationale supported by evidence (Davidson, 2015). The link between demonstrating evidence-based practice and best patient outcomes is of importance when engaging and educating staff and physicians in change management (Rangachari et al., 2015a). Sound evidence is needed to successfully implement change interventions or if unavailable, then consensus is needed among opinion leaders to support the effectiveness (Pronovost, 2011).

Participants in this study clearly viewed themselves as having internal motivation to change practise, as they were autonomous decision makers, accountable for their own decisions. Adaptive challenge speaks to the need to identify what motivates staff in order to maximise 
Running head: Adaptive challenge and aseptic technique

perceived benefits. Leaders who plan to implement change can use health professionals' belief in themselves as autonomous decision makers to generate their 'buy in' by providing evidence of how AT will improve valued outcomes. This decision making involves the 'what's in it for me' question, with the answer for health professionals being the perceived ability to deliver better patient outcomes providing a motivation for change (Pronovost, 2011).

The findings of this study indicated the need to consult with staff early in the process of implementing a change in a health care setting. While practitioners held beliefs about AT based on evidence, they indicated that these beliefs could be influenced by team leaders, colleagues and, by implication, educators. During the implementation of new innovations, it is important to take note of clinicians' attitudes, motivation and concerns and their need for reassurance (McMurray, Chaboyer, Wallis, \& Fetherston, 2010). This theme reflects on the principle of communication and the importance of relationships for the necessity of change but also inviting staff to achieve a consistent goal.

Early and extensive consultation is needed with any, and every, group potentially impacted by the change, which includes detailed feedback and a say in the development of multiple options for implementation (Davidson, 2015). Once staff have been involved with the inception of the change, communication and consultation needs to be an ongoing process (Davidson, 2015). In the current study, the working group consulted prior to implementation and consultation continued via the education program. To sustain improvements in practice staff require detailed communication from management and the opportunity to provide input as initiatives are developed (Saint et al., 2015), and communication needs to be meaningful (Rangachari et al., 2015b).

The social and organisational context within a multidisciplinary team incorporates support, which includes the approach to communication for change. Both a 'top-down' and 'bottomup' approach can be taken to promote successful organisational improvement (Edwards et 
Running head: Adaptive challenge and aseptic technique

al., 2012). The assumption is that the top-down approach disseminates clear, explicit knowledge and direction throughout the health care institution, while bottom-up communication at a local level offers tacit knowledge and understanding within that specific context (Edwards et al., 2012). Solutions to adaptive challenge are held within the collective intelligence of employees at all levels, as they leverage their relationships as resources to foster change (Heifetz \& Laurie, 1997) and should be encouraged to do so.

Within the health care industry, staff members are inundated with rapidly evolving systems, technologies and regulatory frameworks and often expected to achieve more with fewer resources leading to feelings of being overwhelmed (Pronovost, 2011). The emergence of champions from frontline nurses and/or unit managers to initiate process improvements and offer positive reinforcements for change can help in two ways. Firstly, these champions can promote physician/staff engagement and, secondly, facilitate tacit knowledge exchanges between health professionals to enable collective learning and culture change at unit level (Pronovost, 2011; Rangachari et al., 2015b). During change efforts, champions can emerge spontaneously, influencing colleagues through their energy and obvious commitment to the change. Alternatively, 'change leaders' can be authorised by manager or executive to lead the change effort. The change leader is perfectly positioned to be responsible for monitoring the implementation, providing feedback, to offer guidance to all involved and to address barriers to implementation as they are identified (Leeman, Baernholdt, \& Sandelowski, 2006).

Inconsistency from various levels of management with the message of implementation of change was considered a barrier in this setting. This finding aligns with the adaptive leadership principle of providing a clear and consistent goal and inviting all staff to achieve it. A strategy to achieve this is to offer medical staff and nurses training in dressing techniques alongside each other (Aziz, 2009). Other barriers identified by both the medical and nursing 
Running head: Adaptive challenge and aseptic technique

focus groups was that, whilst there was formal orientation to ED for nurses, there was none for doctors who felt that their learning occurred though 'osmosis'.

From the analysis of the five focus groups and emergent themes, adaptive challenges and adaptive leadership were distilled. These factors can provide clear direction to inform implementation of standardised AT practice in similar units in other hospitals.

The limitation to this study was that the AT program was implemented in ED at a time in which there had been a lot of previous change. This may have impacted on ED staff willingness to participate, and overall perceptions of change. Additionally, the data were collected from one ED in one acute hospital. It is possible that the perceptions of health professionals working in other hospitals or clinical settings may differ.

\section{Conclusion}

Findings of this study indicate that using the principles of adaptive leadership are of value when implementing change to practice. Providing evidence to health professionals who see themselves as autonomous practitioners within the ED team prior to and throughout the process of change can assist in obtaining their buy-in and sustained engagement. (Rowley \& Clare, 2011).

\section{Relevance to Clinical Practice}

Reducing the variables of AT by standardising the technique improves the quality of practice and subsequent infection rates (Rowley \& Clare, 2009). While for many practitioners, the implementation of standardised AT requires little more than education and revisiting existing knowledge and skills, others may resist change that challenges their beliefs about infection risk and themselves as autonomous practitioners. Adaptive challenge provides a useful 
Running head: Adaptive challenge and aseptic technique

framework to engage clinical staff in practice improvements, where more than technical information is required to generate and sustain staff 'buy-in'. This approach ensures that all staff members involved in practice change share a consistent goal and communicate clearly to all those expected to apply the AT principles. Structured education commenced early offers a mechanism by which to provide evidence that builds the case for the desired practice and reassures practitioners that their efforts are promoting better outcomes for patients. Ultimately, this knowledge has the potential to inform evidence-based management strategies applicable to health care contexts. Findings from this study build upon what is already known in the literature with regards to providing all practitioners within the multidisciplinary team with evidence relating to the reason for change, the impact during the change process, and results once it has been implemented. The use of a local champion who can motivate colleagues and ensure the plan for change suits the specific environment is an important driver to encourage and sustain buy-in from all staff. 


\section{References}

Australian Commission on Safety and Quality in Health Care. (2012). Safety and Quality Improvement Guide Standard 3: Preventing and Controlling Healthcare Associated Infections. Sydney: ACSQHC Retrieved from https://www.safetyandquality.gov.au/wpcontent/uploads/2012/10/Standard3_Oct_2012_WEB.pdf.

Aziz, A. (2009). Variations in aseptic technique and implications for infection control. British Journal of Nursing, 18(1), 26-31.

Davidson, J. (2015). What's all the buzz about change management? Healthcare Managament Forum, 28(3), 118-120. doi:10.1177/0840470415570174

Edwards, R., Sevdalis, N., Vincent, C., \& Holmes, A. (2012). Communication strategies in acute health care: evaluation within the context of infection prevention and control. Jounal of Hospital Infection, 82, 25-29.

Gale, N., Heath, G., Cameron, E., Rashid, S., \& Redwood, S. (2013). USing the frameowrk method for the analysis of qualitative data in multi-disciplinary health research. BMC Medical Research Methodology, 13, 117.

Gleeson, P. (2017). What is train the trainer model? Retrieved from https://work.chron.com/traintrainer-model-5463.htm

Grol, R. (2001). Successes and failures in the implementation of evidence-based guidelines for clinical practice. Medical Care, 39(Supp 2), ii-46-ii-54.

Guba, E. G., \& Lincoln, Y. S. (2005). Paradigmatic Controversies, Contradictions, and Emerging Confluences. In N. K. Denzin \& Y. S. Lincoln (Eds.), The Sage Handbook of Qualitative Research (3rd ed., pp. 191-215). Thousand Oaks: Sage Publications, Inc.

Haeusler, J. M. C. (2010). Medicine needs adaptive leadership. Physician Executive Journal, MarchApril, 12-15.

Heifetz, R., \& Laurie, D. (1997). The work of leadership. Harvard Business Review, (JanuaryFebruary) 1997, 124-136.

Heifetz, R., Linsky, M., \& Grashow, A. (2009). The practice of adaptive leasdership: Tools and tactics for changing your organization and the world. Cambridge, MA: Harvard Business Press.

Leeman, J., Baernholdt, M., \& Sandelowski, M. (2006). Developing a theory-based taxonomy of methods for implementating change in practice. Journal of Advanced Nursing, 58(2), 191200. doi:10.1111/j.1365-2648.2006.04207.x

McMurray, A., Chaboyer, W., Wallis, M., \& Fetherston, C. (2010). Implementing bedside handover: startegies for change management. Journal of clinical nursing, 19, 2580-2589. doi:10.1111/j.1365-2702.2009.03033.x

Mitchell, B. G., Shaban, R. Z., MacBeth, D., Wood, C.-J., \& Russo, P. L. (2017). The burden of healthcare-associated infection in Australian hospitals: A systematic review of the literature. Infection, Disease \& Health, 22(3), 117-128. doi:10.1016/j.idh.2017.07.001

Pronovost, P. (2011). Navigating adaptive challenges in quality improvement. BMJ Quality Safety, 20(7), 560-563.

Rangachari, P., Madaio, M., Rethemeyer, R., Wagner, P., Hall, L., Roy, S., \& Rissing, P. (2015a). Cumulative impact of periodic top-down communications on infection prevention practices and outcomes in two units. Health Care Managament Review, 40(4), 324-336.

Rangachari, P., Madaio, M., Rethemeyer, R., Wagner, P., Hall, L., Roy, S., \& Rissing, P. (2015b). The evolution of knowledge exchanges enabling successful practice change in two intensive care units. Health Care Managament Review, 40(1), 65-78.

Rangachari, P., Rissing, P., \& Rethemeyer, R. (2013). Awareness of Evidence-Based Practices Alone Does Not Translate to Implementation: Insights From Implementation Research. Quality Management in Health Care, 22(2), 117-125.

Rowley, S., \& Clare, S. (2009). Improving standards of aseptic practice through an ANTT trust-wide implementation process: a matter of prioritisation and care. Jounal of Infection Prevention, 10(1), s18-s23. 
Rowley, S., \& Clare, S. (2011). ANTT: a standard approach to aseptic technique. Nursing Times, 107(36), 12-14.

Rowley, S., Clare, S., Macqueen, S., \& Molyneux, R. (2010). ANTT v2: an updated practice framework for aseptic technique. British Journal of Nursing, 19(5), S5-11.

Saint, S., Fowler, K., Sermak, K., Gaies, E., Harrod, M., Holland, P., . . Krein, S. (2015). Introducing the No Preventable Harms campaign: Creating the safest health care system in the world, starting with catheter-associated urinary tract infection prevention. American Journal of Infection Control, 43, 254-259.

Schinnerer, J. (2018). The power of positive motivation. Retrieved from https://psychcentral.com/lib/the-power-of-positive-internal-motivation/

Schneider, Z., Whitehead, D., LoBiondo-Wood, G., \& Haber, J. (2014). Mursing and midwifery research methods and appraisal for evidence-based practice (5th ed.). NSW: Elsevier Australia. 
1 Table 1: Themes of facilitators and barriers with sample quotations of adaptive challenge and adaptive leadership

\begin{tabular}{|c|c|c|c|}
\hline Theme & Definition & Sample adaptive challenge themes from participants & $\begin{array}{l}\text { Sample adaptive leadership } \\
\text { recommendations }\end{array}$ \\
\hline Motivation & $\begin{array}{l}\text { Internal and/or external and } \\
\text { can be considered drivers } \\
\text { for stimulating change in } \\
\text { practice. }\end{array}$ & $\begin{array}{l}\text { "If there's a decent reason behind it people will comply } \\
\text { but if people aren't understanding why [they won't] .... } \\
\text { if I can't understand the reason behind it, I'd be less likely } \\
\text { to enforce it on other people in my team as well." (Nurse, } \\
\text { FG1) } \\
\text { "If someone can show us that it actually makes a difference, } \\
\text { that's one thing ... the evidence?" (Doctors, FG3) } \\
\text { "with the feedback you would get, people more willing to } \\
\text { participate because they're going 'ok there is improvement } \\
\text { here"” (Nurses, FG1). }\end{array}$ & $\begin{array}{l}\text { Prior to implementing change to practice: } \\
\text { - } \\
\text { provide specific evidence to support } \\
\text { the need for change and ask for } \\
\text { possible solutions from the } \\
\text { multidisciplinary team; } \\
\text { - } \quad \text { during the implementation and on } \\
\text { completion of strategies, provide } \\
\text { evidence of results associated with } \\
\text { the change; } \\
\text { The provision of evidence and asking for } \\
\text { input on potential solutions, raises } \\
\text { awareness of each individual health } \\
\text { practitioner as an autonomous practitioner } \\
\text { and able to prioritise the care of the patient }\end{array}$ \\
\hline Relationships & $\begin{array}{l}\text { Relationships between } \\
\text { individual staff members, } \\
\text { and between } \\
\text { multidisciplinary team } \\
\text { members. Includes peer } \\
\text { support and peer pressure } \\
\text { to foster change and to do } \\
\text { 'the right thing'. }\end{array}$ & $\begin{array}{l}\text { "Peer support so knowing that you peers are taking on the } \\
\text { change as well and being able to remind each other" (FG2 } \\
\text { Post N) } \\
\text { "They kind of just tell us to do it or if we don't, they tell } \\
\text { us again" (FG2, Post N) }\end{array}$ & 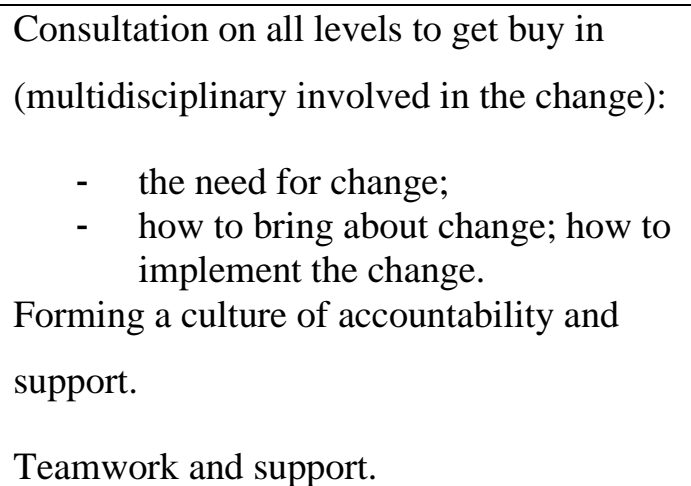 \\
\hline
\end{tabular}




\begin{tabular}{|c|c|c|c|}
\hline $\begin{array}{l}\text { Education } \\
\text { delivery }\end{array}$ & $\begin{array}{l}\text { Education to introduce, } \\
\text { implement and evaluate the } \\
\text { change. Flexible to meet } \\
\text { the needs of the specific } \\
\text { environment it is to be } \\
\text { implemented in, suitable to } \\
\text { meet the needs of the } \\
\text { multidisciplinary team and } \\
\text { feedback. }\end{array}$ & $\begin{array}{l}\text { "the way the hospital did it's been quite easy for you to } \\
\text { incorporate into your practice." (FG1Post N). } \\
\text { "It would be good you were told it when you start here, } \\
\text { and all the new doctors as well and the new nursing staff, } \\
\text { we're just like this is how we do it here." (FG1 Pre N) } \\
\text { 'Learning "by osmosis" (Doctor, FG 3), which meant: } \\
\text { You have the [undergraduate] training ... } \\
\text { but you learn on the job. People learn to put } \\
\text { cannulas and learn AT from . . observing } \\
\text { other people doing it. And so if the person } \\
\text { teaching them isn't doing it the right way, } \\
\text { they'll learn it not the right way as well. } \\
\text { (Doctors, FG 3) }\end{array}$ & $\begin{array}{l}\text { Programme is flexible in its approach to } \\
\text { delivery and time to complete various } \\
\text { delivery approaches: } \\
\text { - e-learning, } \\
\text { - } \quad \text { core competencies, } \\
\text { - } \quad \text { orientation, } \\
\text { - } \quad \text { refresher sessions, } \\
\text { - posters, } \\
\text { - } \quad \text { discussion at morning meetings. } \\
\text { Programme is available to all staff in ED. }\end{array}$ \\
\hline $\begin{array}{l}\text { Management } \\
\text { directive }\end{array}$ & $\begin{array}{l}\text { Implementation of the } \\
\text { proposed change by } \\
\text { hospital management }\end{array}$ & $\begin{array}{l}\text { "No, I just think you educate, you bring it in that's it. } \\
\text { People just comply" (FG } 1 \text { Pre N) } \\
\text { "So if people you know train up the middle ground and } \\
\text { then they inform seniors and seniors know they have to } \\
\text { care, I don't know it's nice it's not to the general hierarchy, } \\
\text { People are more adaptive to it." (FG2 Pre N) }\end{array}$ & $\begin{array}{l}\text { Consistency in the message delivered by all } \\
\text { managers. } \\
\text { Use of a bottom up approach in the delivery. } \\
\text { Making the change mandatory } \\
\text { Support: }\end{array}$ \\
\hline
\end{tabular}


Running head: Adaptive challenge and aseptic technique

\begin{tabular}{|l|l|l|}
\hline & & $\begin{array}{l}\text { from management (not always a top } \\
\text { down approach); } \\
\text { from colleagues in the department, a } \\
\text { change champion. } \\
\text { just comply . . 'this is practice', 'this is going to happen, } \\
\text { deal with it guys' . . you end up being in the minority if } \\
\text { you don't do it. You will get pulled aside." (Nurses, FG1) }\end{array}$ \\
\end{tabular}


Running head: Adaptive challenge and aseptic technique 